Supplement of Atmos. Chem. Phys., 14, 9343-9362, 2014

http://www.atmos-chem-phys.net/14/9343/2014/

doi:10.5194/acp-14-9343-2014-supplement

(C) Author(s) 2014. CC Attribution 3.0 License.

(c) (i)

Atmospheric

Chemistry

and Physics

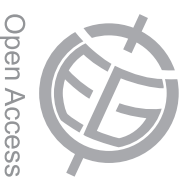

Supplement of

\title{
Evaluation of IASI-derived dust aerosol characteristics over the tropical belt
}

\section{Capelle et al.}

Correspondence to: A. Chédin (chedin@1md.polytechnique.fr) 


\section{Supplementary Material}

Paper title: "Evaluation of IASI derived dust aerosols characteristics over the tropical belt" by V. Capelle et al. (2013).
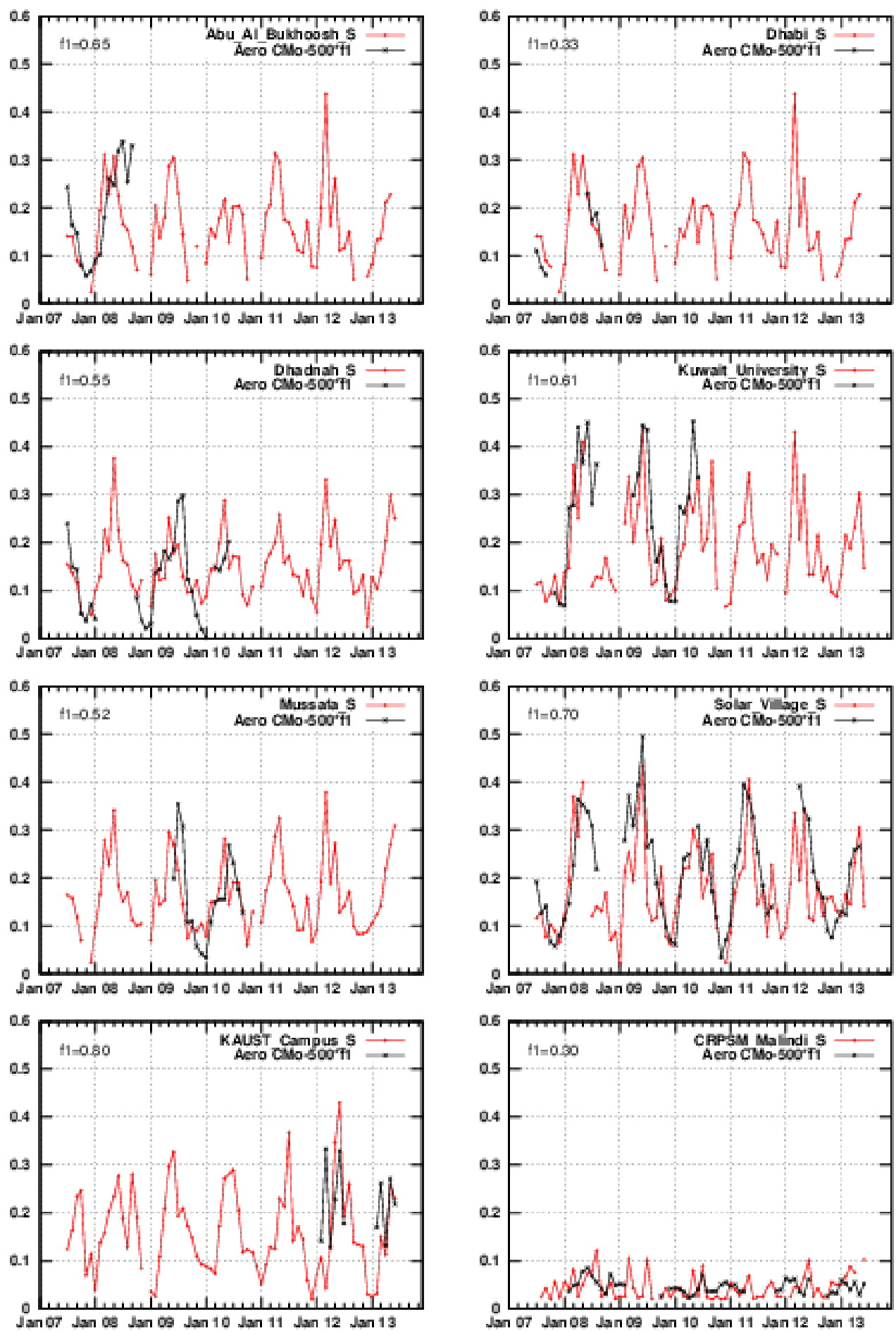

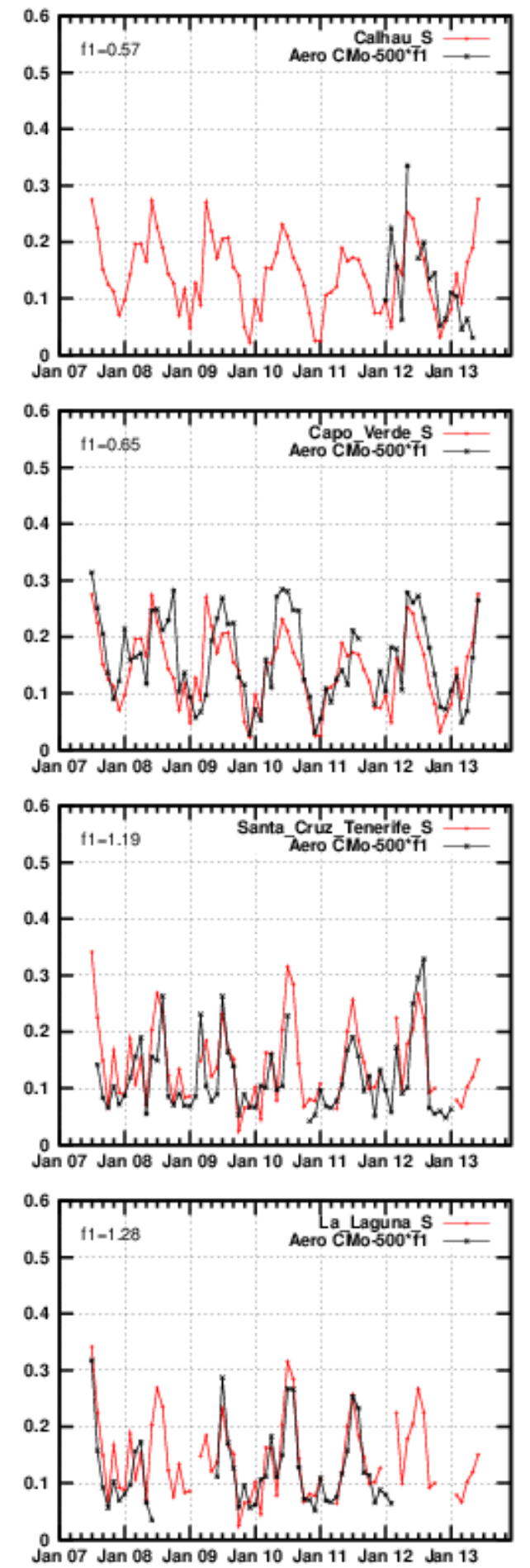
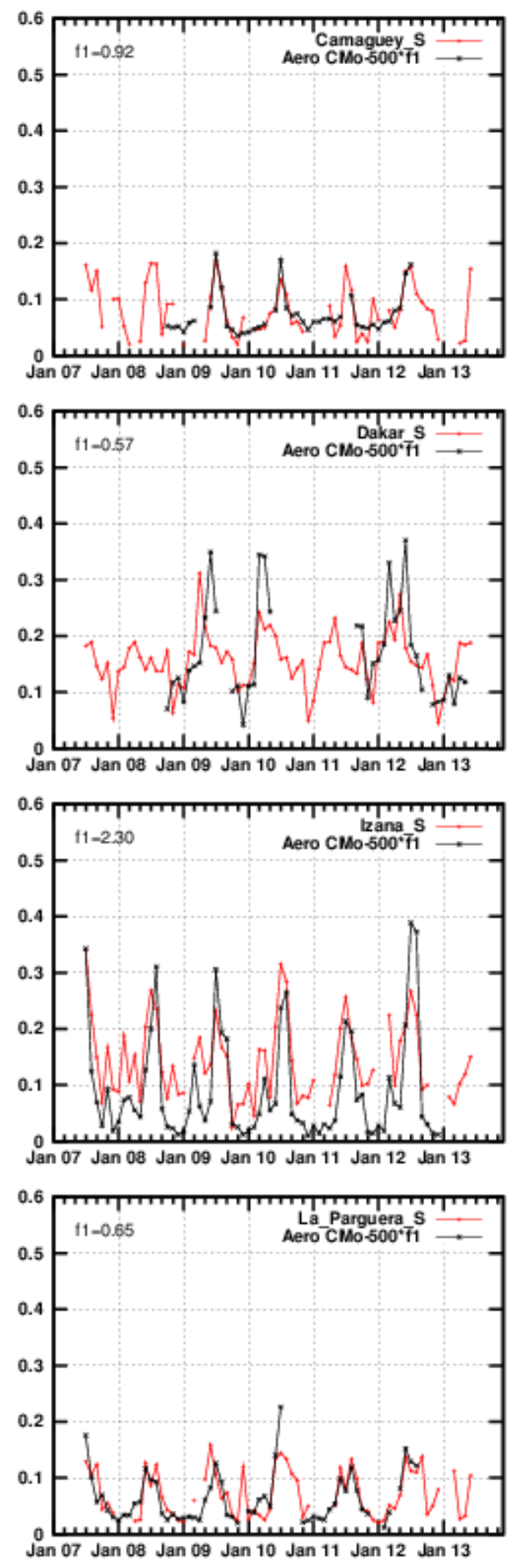

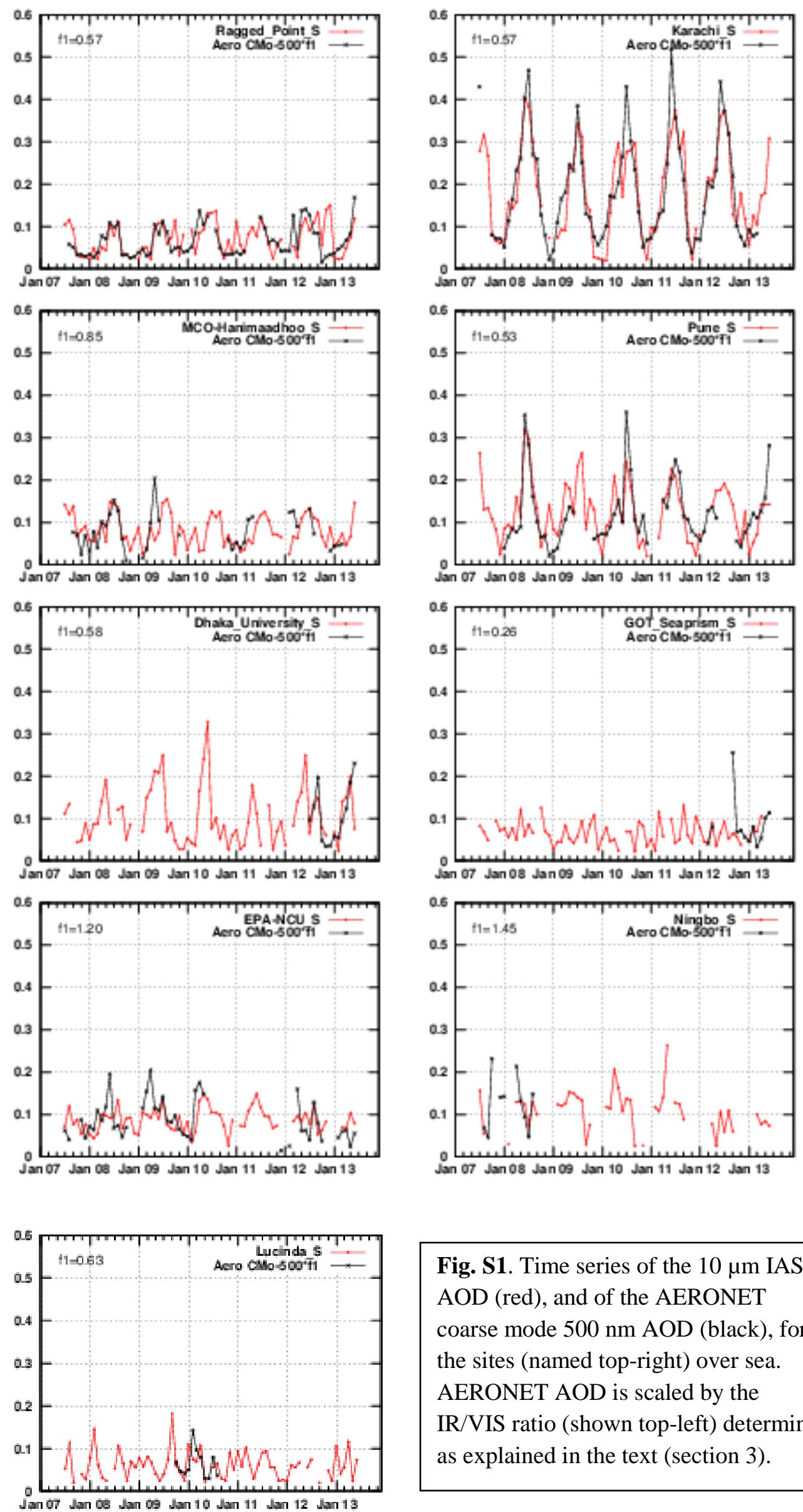

Fig. S1. Time series of the $10 \mu \mathrm{m}$ IASI AOD (red), and of the AERONET coarse mode $500 \mathrm{~nm}$ AOD (black), for the sites (named top-right) over sea. AERONET AOD is scaled by the IR/VIS ratio (shown top-left) determined as explained in the text (section 3). 

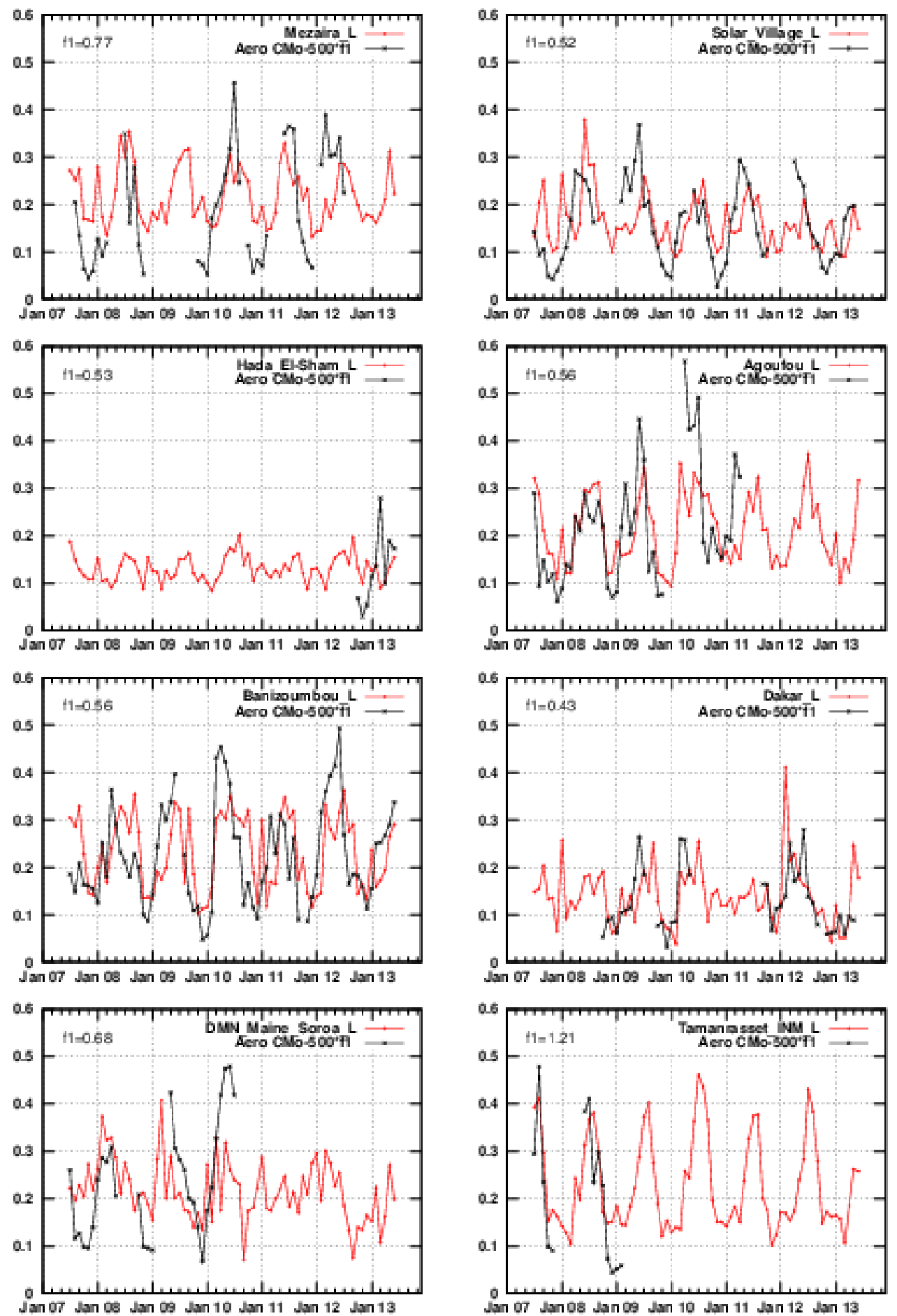

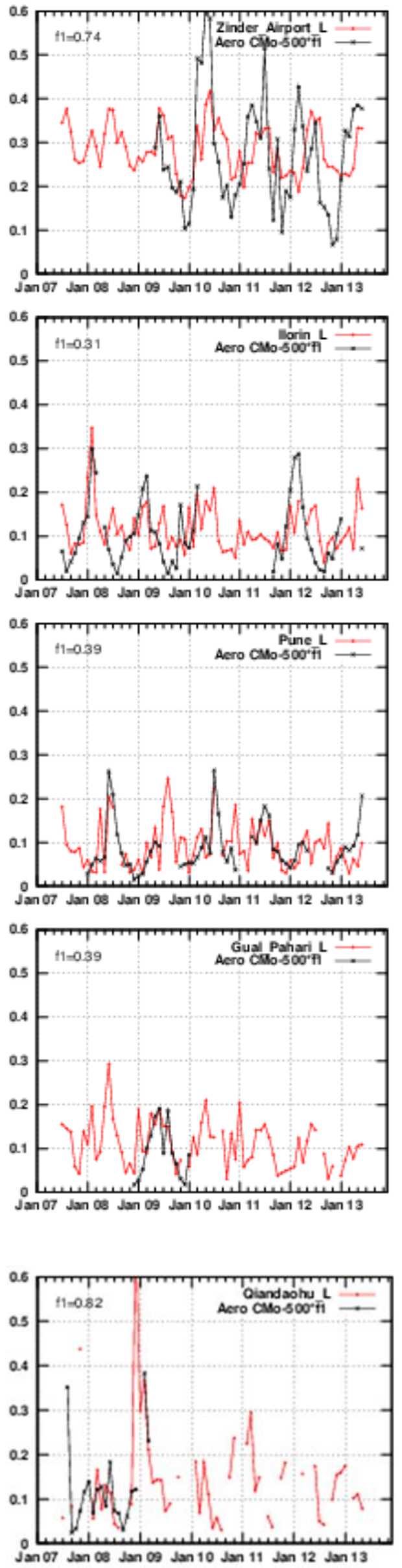
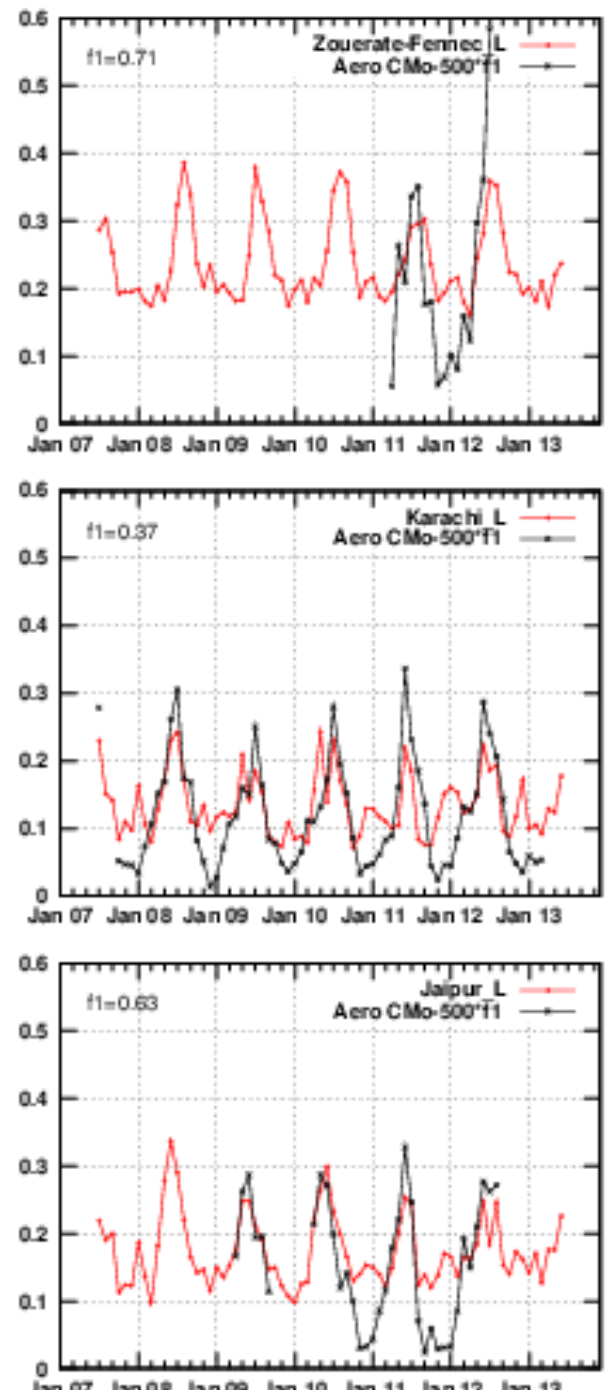

13 רפل 12

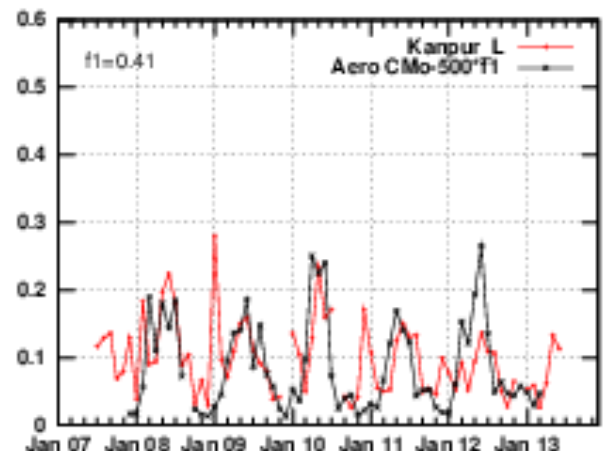

Fig. S2. Same as Fig. S1 for the sites over land. 


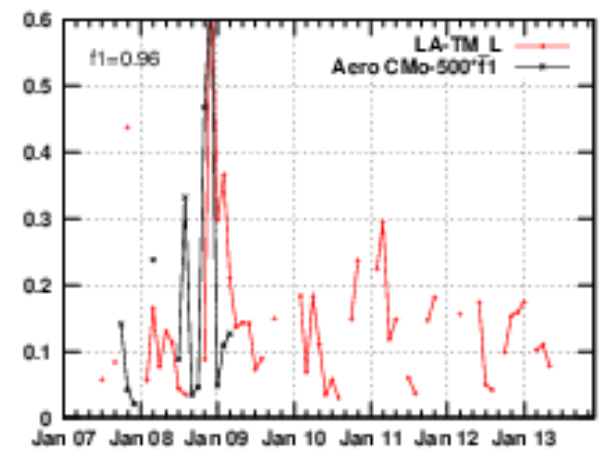

Fig. S3. Same as Fig. S1 for the site of LA_TM close to the site of Qiandaohu. Note the strong event in December 2008 seen by both IASI and AERONET.
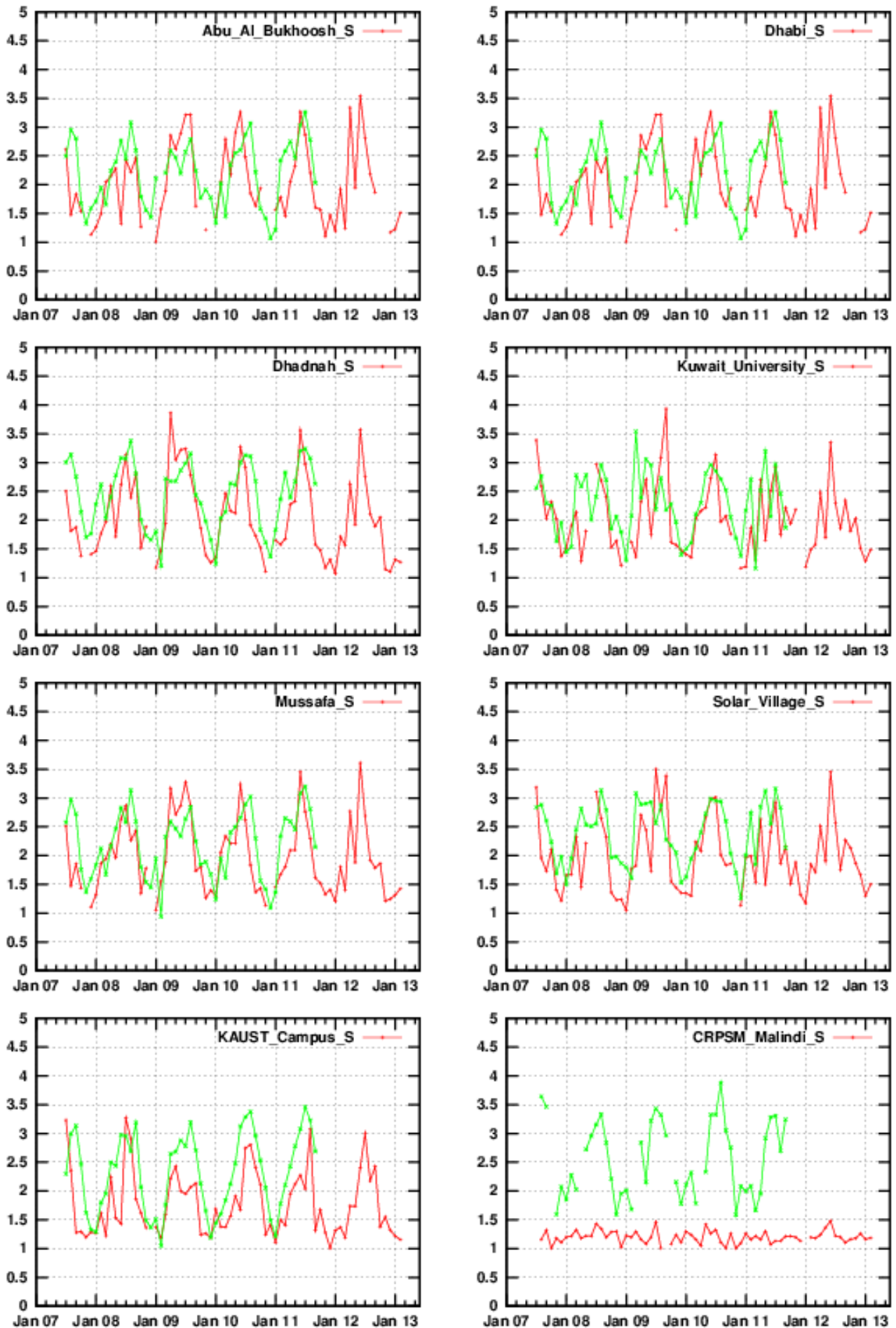

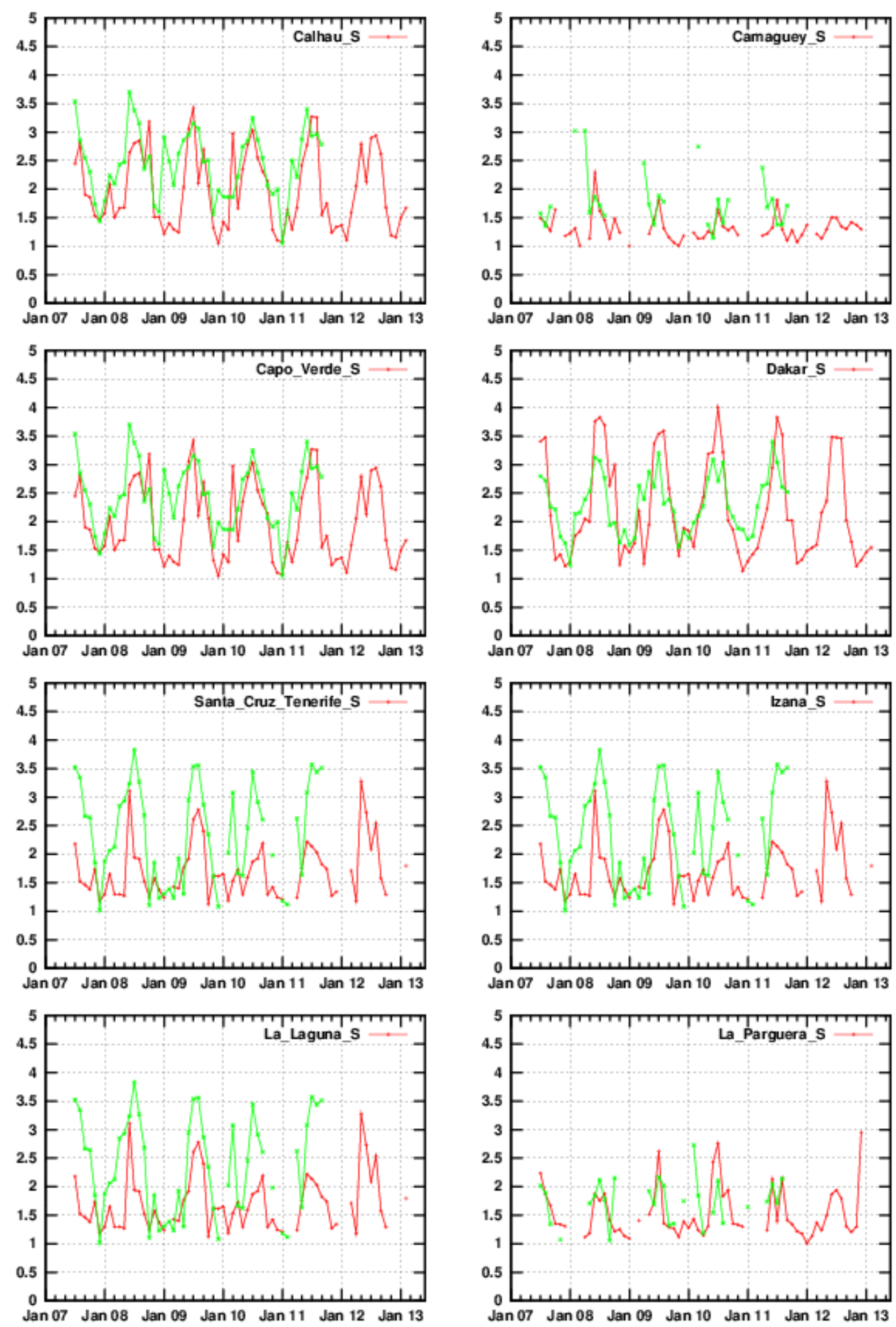

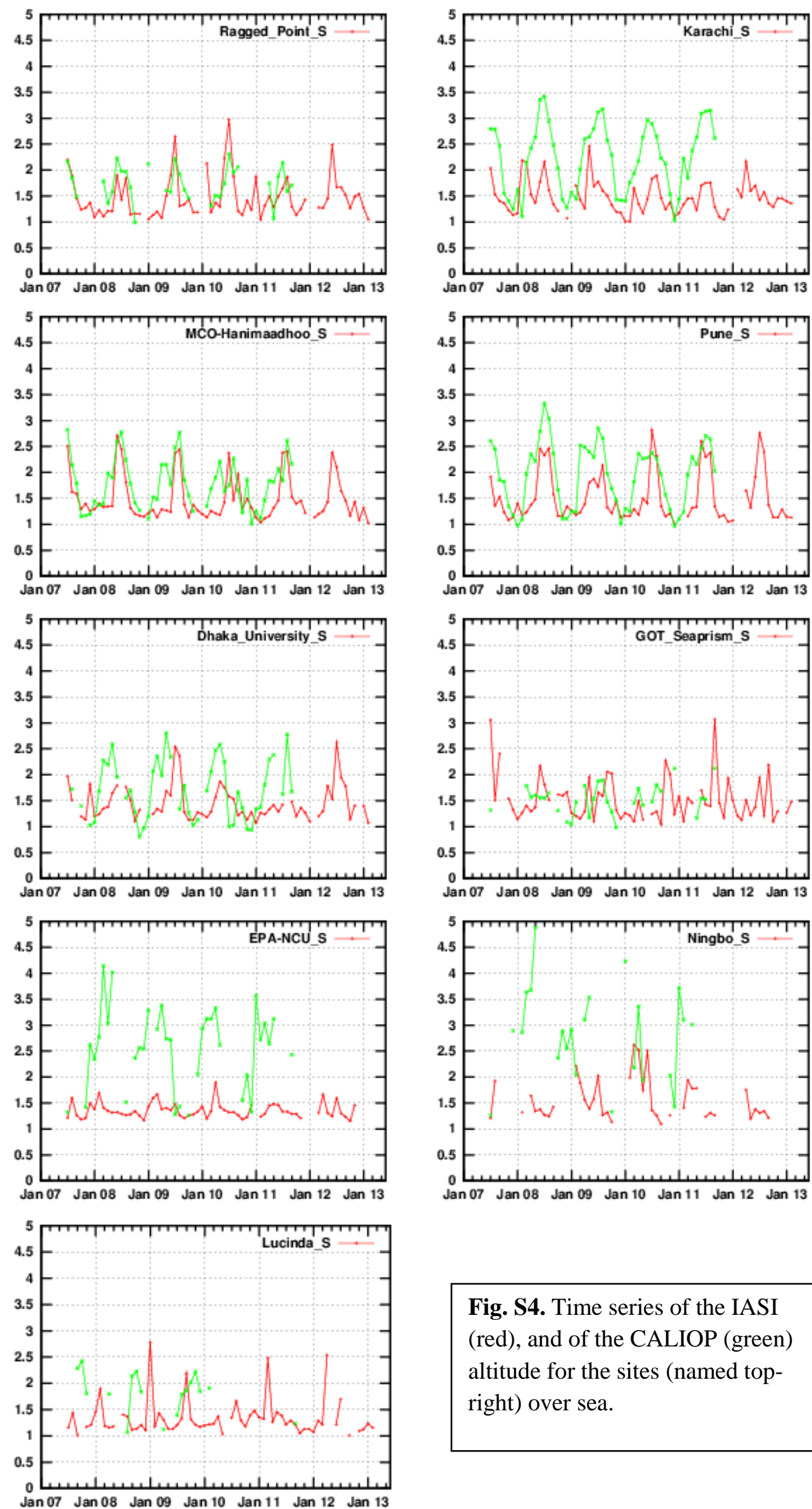

Fig. S4. Time series of the IASI (red), and of the CALIOP (green) altitude for the sites (named topright) over sea. 